\title{
Evaluation of Natural Radioactive Elements and Hazardous Indexes Using High Pure Germanium Gamma Ray Spectroscopy in Sekota, Waghimra, Zone, Ethiopia
}

\author{
Baye Zinabe Kebede*, Tadesse Gebeyehu* \\ Department of Physics, College of Natural Science, Mekdela Amba University, Mekdela Amba, Ethiopia \\ Email address: \\ bayezinabe82@gmail.com (B. Z. Kebede), tadesegebeyehu@gmail.com (T. Gebeyehu) \\ ${ }^{*}$ Corresponding author
}

To cite this article:

Baye Zinabe Kebede, Tadesse Gebeyehu. Evaluation of Natural Radioactive Elements and Hazardous Indexes Using High Pure Germanium Gamma Ray Spectroscopy in Sekota, Waghimra, Zone, Ethiopia. American Journal of Physics and Applications. Vol. 9, No. 2, 2021 , pp. 48-52. doi: 10.11648/j.ajpa.20210902.14

Received: May 8, 2021; Accepted: June 30, 2021; Published: July 9, 2021

\begin{abstract}
This research paper desired to illustrate the presence of naturally occurring radioactive minerals concentration and the way how naturally occurring radioactive minerals were identified in Wag-himra iron ore deposit soil site. The deposit area covers five Kebelles of the border of Sekota, Ziquale and Abergelle districts. We were used high pure germanium detector to identify the presence of natural occurring radioactivity concentration in iron ore/alloy deposit soil, and applied appropriate research methodology particularly experimental design were more preferable. The researcher was collected samples from ten places across iron ore deposit area by using judgmental sampling techniques and prepared as a desirable manner. The chosen sample was sealed for four weeks in order to obtain secular equilibrium, wherein the rate of decay of the daughter's equivalent that of the parent. Radium equivalent activity, external hazard index and representative gamma index of the sample were 56.19, $0.1515,0.804,0.408,0.00011(\mathrm{~Bq} / \mathrm{kg})$ respectively. However, internal hazard index was slightly approaching to recommended value and it may cause the significant radiation hazard through long dwelling to the area. This study NORM was analysis from sample of soil from at mineral/iron ore deposit area. The natural occurrence of radioactive materials identified in the samples were ${ }^{238} \mathrm{U},{ }^{232} \mathrm{Th}$ and ${ }^{40} \mathrm{~K}$. The radiation hazardous were external and internal index.
\end{abstract}

Keywords: Radiation, Concentration, Hazard Index, Radium Equivalent and Radionuclide

\section{Introduction}

Henri Becquerel discovered radioactivity in 1986. It is a process in which an unstable parent nucleus spontaneously transforms into one or more daughter nuclei that are more stable than the parent nucleus due to increased binding energies per nucleon than the parent nucleus [1]. The nucleus may also be unstable, and it will decay further a chain of radioactive decay until it begins to take on a configuration [2]. Radioactive decay is commonly caused by the formation of energetic particles that can be used in industry, agriculture, and medicine. There are 2 kinds of radioactive nuclides (radio nuclides): It is a natural artificially produced or formed by man [3]. The man-made (artificial) radionuclide is manufactured by bombarding or very long-lived nuclides with energetic particles produced by machines of various kinds, whereas the naturally radioactive elements are found by nature on the surface of the earth as a form of ore and in the atmosphere with very long-lived parents that have half-lives of the order of the age of the earth [4]. The term NORM refers to naturally radioactive materials. The majority of NORM contains radionuclides from the so-called long-lived "primordial" decay chains, that result from the decay of U-238, U-235, Th-232, as well as other long-lived radio nuclides such as K-40 [5]. Even though all soils and rocks are naturally radioactive, all ores are just as good. The radio nuclides that occur naturally can be divided into those that occur singly those that are components of three chains of radioactive elements [6]. The three remaining radioactive element chains and the long-living primordial nuclide ${ }^{40} \mathrm{~K}$ make up the majority of the external background radiation dose from 
radioactivity to which humans are exposed. Of the 22 identified cosmogonic nuclides, only four, $14 \mathrm{C}, 3 \mathrm{H}, 22 \mathrm{Na}$, and $7 \mathrm{Be}$, have any effect on human doses [7]. In nature, and a few other uranium and thorium nuclides fission, be it spontaneously or as a result of interactions with neutrons emitted by cosmic rays or other natural sources [8]. The half-life of ${ }^{235} \mathrm{U}$ due to spontaneous fission is between $10^{15}$ and $10^{16}$ years, which means that decay by this process proceeds at a rate less than $10^{-7}$ of that due to an emission [9]. Others of the heavy nuclides undergo spontaneous fission with half-lives that range from $10^{14}$ to $10^{20}$ years [10]. Many transuranic elements, such as plutonium, neptunium, and americium, which now exist because they have been produced artificially, must have existed in nature at one time, but their half-lives are so short that they disappeared long ago. However, some of the transuranic elements are produced in minute amounts by naturally occurring neutrons that result from cosmic radiation and spontaneous fission of uranium isotopes. Uranium is found in all rocks and soils [11]. The high uranium content of phosphate rocks is reflected in correspondingly high uranium concentrations in commercial phosphate fertilizers [12]. The overall effect of soil development results in the average soil concentration of uranium being less than the average rock concentration [13]. Uranium occurs in traces in many commercial products [14]. Radioactive equilibrium is the term usually used to explain the state when the members of the radioactive series decay at the same rate as they are produced [15]. There are three predominant cases of the state of equilibrium, but for this study, the researchers explained only the secular equilibrium. Secular Equilibrium: A steady-state condition in which the parent's half-life is significantly greater than that of the daughter [16].

\section{Material and Method}

This study was experimental because the major purpose of experimental research focuses on cause effect relations between the variables (independent and dependent variables). Experimental research can be qualitative or quantitative. It can be done in a lab-setting or in the field.

\subsection{Materials We Used}

The study required all the necessary nuclear physics laboratory equipment, such as high pure germanium gamma ray spectroscopy, stainless steel cylindrical sampler, $10 \mathrm{~cm}$ lead layer shield, high power supply, oven, Polyethylene beaker, Mortar and Pestle (grinder).

\subsection{Sample Collection and Preparation}

Judgmental sampling was used to select some parts of the iron ore deposit soil in which the researchers believed that naturally occurring radionuclide minerals would be available. The sample was drawn from the targeted population by using a convenience-sampling technique. Although, non-probability sampling has problems related to selection bias, in small inquiries and research by individuals, the sampling technique is adopted. Thus, smaller chunks of a unit sample were chosen to represent the relevant attributes of the whole of the units. Because convenience sampling is conducted based on my interests, it was only considered as a sample frame for the purposes of this study. The iron ore deposit soil area was first divided into ten clusters based on information about iron ore soil deposition from the entire area, and then each cluster was divided into four units that differed from the $300 \mathrm{~m}$ in the study area. Samples were taken from a depth of $25-30 \mathrm{~cm}$ after removing the possible contamination on the top surface of undisturbed soil [1]. As a result, a 500g-1000g chunk was placed in a plastic container. Soil samples were taken from ten different locations at the iron ore deposit site in the Wag-himra zone of Ethiopia. After completing the collection of samples from each cluster, mix each sample into one polyethylene plastic. Finally, by quartering them equally in magnitude into four, then pick one of the remaining desired quantities.

\subsection{Sample Preparation}

The sample of soil was dried at room temperature for five consecutive days and dried in an oven at a temperature of $105^{\circ} \mathrm{C}$ for 24 hours to ensure that moisture was completely removed and until the sample had a constant weight. From the selected sample of $1 \mathrm{~kg}$ of soil, the researcher prepared two samples and each sample was measured at $500 \mathrm{~g}$ by a digital beam balance. The samples were crushed, homogenized, and sieved through a standard $2 \mathrm{~mm}$ mesh size, which is optimal for enrichment with heavy minerals. Weight samples were placed in polyethylene beakers of $300 \mathrm{~cm}^{3}$ volume each by the researchers. The beakers were completely sealed for four weeks to achieve secular equilibrium, which takes place when the rate of decay of the daughter represents that of the parent. This step is necessary to ensure that radon gas is confined within the volume and the decay products also remain in the sample.

\subsection{HPGe Detector}

In this research, analyses of the sample soils were performed with a computer-based gamma-spectrometry system with software called G-2000 for qualitative and quantitative determination of gamma-emitting radionuclides of NORM. The High Purity Germanium (HPGe) detector is coupled to a Multi-Channel Analyzer (MCA), and has cooled with liquid nitrogen (cryostat) to temperature of $-196.25^{\circ} \mathrm{C}$ to reduce noise and for good resolution. Increased cancer across all of life, at a given level of exposure, risk, represents the of developing cancer over a lifetime. The relative efficiency the detector is $70 \%$ with an energy resolution of $1.9 \mathrm{keV}$ at a gamma ray energy of $1332 \mathrm{keV} \gamma$-emission of Co-60. The measurement of activity concentrations of the radionuclides ${ }^{238} \mathrm{U},{ }^{232} \mathrm{Th},{ }^{226} \mathrm{Ra}$ and ${ }^{40} \mathrm{~K}$ in the sample was evaluated by using software associated with the detector of GENIE-2000 software. The gamma ray spectra were analyzed. In all measurements of radiation, the background radiation outside and inside the detector shielding was measured using an empty Marnelle beaker. The activity concentrations of the 
sample were measured in the same manner as the background radiation. This background radiation was subtracted from the measured gamma spectrum of the sample before calculating the activity concentration. The two soil samples were each counted for 10 hours $(36,000$ seconds) for two consecutive days to get measurable concentration activity because the amplifier must take a longer time to process the signal and develop its linear pulse, or else not all of the incident energy would be reflected in that pulse.

\subsection{Data Analysis}

The major objective of this study was the estimation of naturally occurring radionuclide mineral concentration and radiation in soil samples of the Wag-himra iron ore deposit area. In order to achieve/evaluate those mentioned objectives of the study, a different technique has been applied. For instance, soil samples were sealed for 4 weeks in a plastic beaker and finally, by using a high pure germanium (HPGe) detector, the concentration of NORM was analyzed.

\subsection{Radiation Hazard Indices and Radium Equivalent}

The radium equivalent concept allows a single index or number to describe the gamma output from different mixtures of uranium, thorium, and ${ }^{40} \mathrm{~K}$ in soil samples from different locations.

$$
\text { Raeq }=\mathrm{A}_{\mathrm{U}}+1.43 \mathrm{~A}_{\mathrm{Th}}+0.077 \mathrm{~A}_{\mathrm{K}}
$$

Where; $A_{U}, A_{T h}$ and $A_{K}$ are the specific activity of ${ }^{238} U$, ${ }^{232} \mathrm{Th}$ and ${ }^{40} \mathrm{~K}(\mathrm{~Bq} \mathrm{~kg}-1)$, respectively. The external hazard index $(\mathrm{Hex})$ and internal hazard index $\left(\mathrm{H}_{\text {in }}\right)$ can be define.

$$
\begin{aligned}
\mathrm{H}_{\mathrm{ex}} & =\frac{A U}{370 B q / k g}+\frac{A T h}{259 B q / k g}+\frac{A K}{4810 B q / k g} \\
\mathrm{H}_{\mathrm{in}} & =\frac{A U}{185 B q / k g}+\frac{A T h}{259 B q / k g}+\frac{A K}{4810 B q / k g}
\end{aligned}
$$

\subsection{Evaluation of Gamma Radiation Level Index and Excess Lifetime Cancer Risk}

This index is very essential to control $\gamma$-radiation annual effective doses and in monitoring radiation inside of the body which was calculated as follow;

$$
\mathrm{I}_{\gamma}=\frac{A R a}{150}+\frac{A T h}{100}+\frac{A K}{1500} \leq 1
$$

Excess cancer across all of life, at a given level of exposure to risk, represents the risk of developing cancer over a lifetime. People may be exposed to -radiation because -rays emitted from soil can easily travel long distances to the surrounding environment, and adverse health effects may occur after an extended period of exposure. The absorbed dose rate, annual effective dose, internal and external hazard indices, and internal and external hazard indices were discovered to be extremely important in understanding the health hazard effect of -radiation exposure radionuclides. External hazard indices are calculated to specify soil type and limit the limiting value of the acceptable equivalent dose.

\section{Result and Discussion}

We have discussed the results of the gamma radiation level index and the excess lifetime cancer risk, external and internal radiation hazard index. The composite samples prepared from the ten soil samples collected from the Wag-himra iron ore deposit area were assigned to the sample codes S1 and S2, but the results of the two were the same. The study also focused on the radiation index with radium equivalent activity.

Table 1. Gamma radiation risk assessment.

\begin{tabular}{llllll}
\hline Sample code & $\begin{array}{l}\text { Raeq } \\
(\mathbf{B q} / \mathbf{k g})\end{array}$ & Hex & Hin & I & ELCR \\
\hline S1 & 56.19 & 0.1517 & 0.803 & 0.407 & 0.00012 \\
S2 & 56.19 & 0.1512 & 0.805 & 0.409 & 0.0001 \\
Mean & 56.19 & 0.1515 & 0.804 & 0.408 & 0.00011 \\
worldwide average & $<370$ & $<1$ & $<1$ & $<1$ & $<1$ \\
\hline
\end{tabular}

It shows soil sample result of radium equivalent activity (Raeq), external hazard index (Hext), internal hazard index (Hint) and $\gamma$-level index, and were less than the limited value recommended by $[16,17]$. From the assessment soil sample of iron ore deposit area in Wag-himra an internal hazard index value was slightly near to limited value recommended by [16].

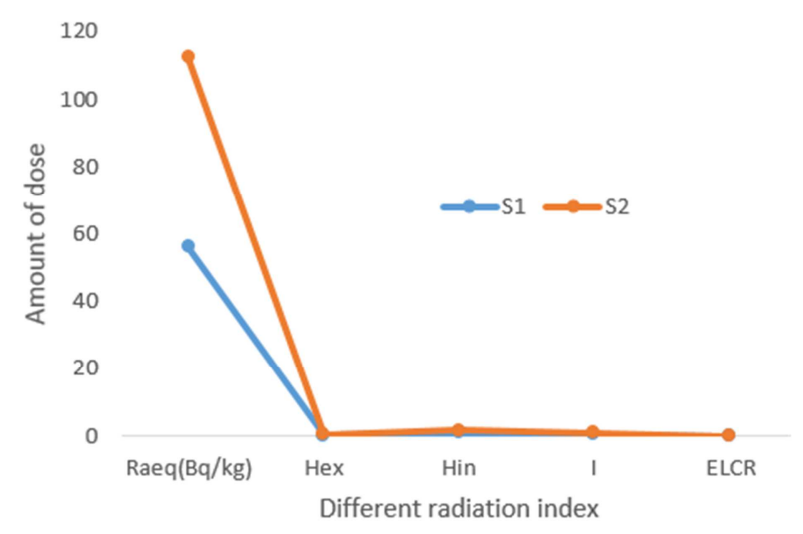

Figure 1. Radiation dose for different radiation index.

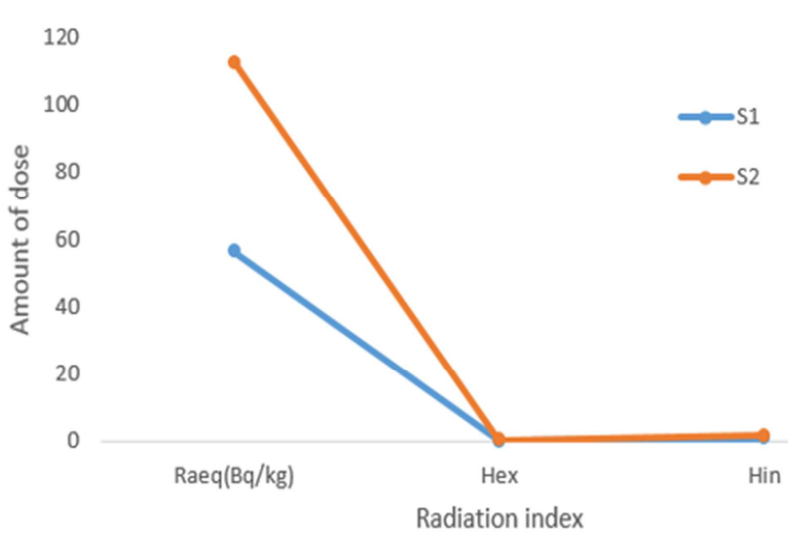

Figure 2. Radium equivalent, external and internal hazarded index.

The various radiation indexes clearly stated that the sample was different because of radium equivalent activity (Raeq), external hazard index (Hext), internal hazard index (Hint). It was discovered that the radium equivalent activity dose was 
significantly higher than the others, indicating that it increases the risk of cancer disease.

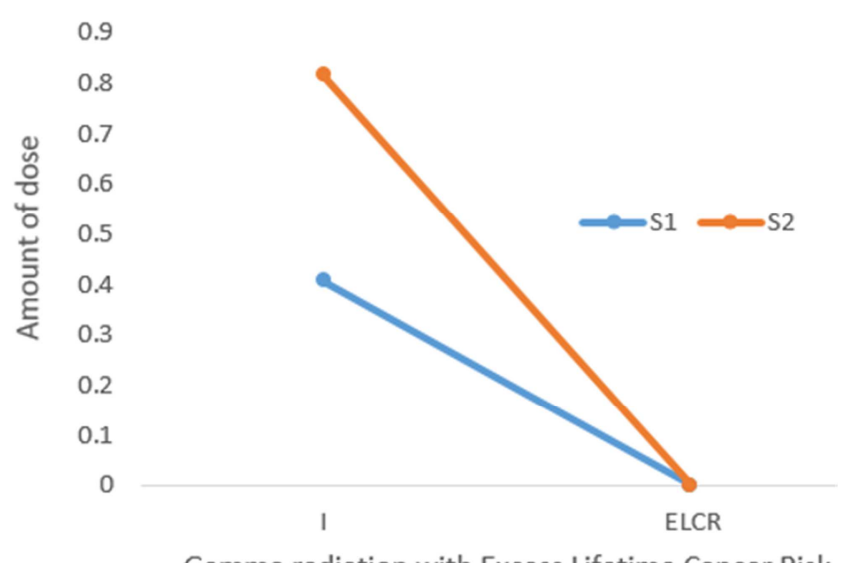

Figure 3. Gamma radiation index with excess life time cancer risk.

Excess cancer across all of life, at a given level of exposure to risk, represents the risk of developing cancer over a lifetime. People may be exposed to -radiation because -rays emitted from soil can easily travel long distances to surround the environment, and adverse health effects may occur after an extended period of exposure.

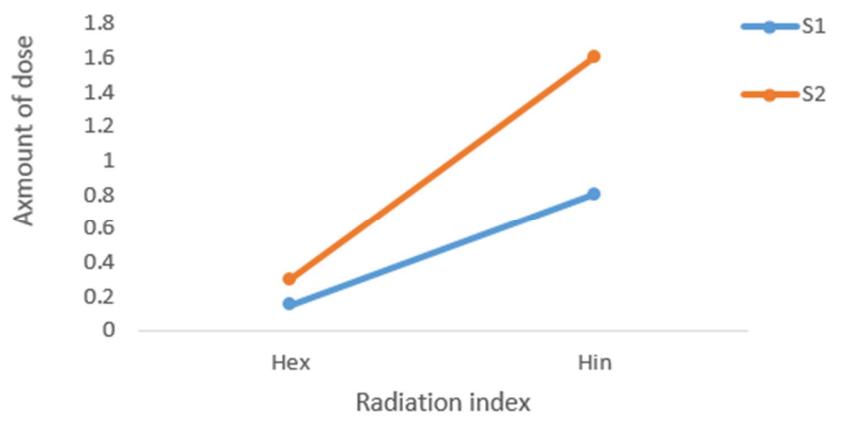

Figure 4. External with internal radiation hazard index's.

Internal and external hazard indices are extremely important for understanding the health hazards of radionuclide -radiation exposure. External hazard indices are calculated to specify soil type and limit the limiting value of the acceptable equivalent dose. As a consequence of this, it may pose a risk over the course of a person's life. In general, measuring gamma radiation for mineral deposit areas of soil is critical for measuring individual hazards. For the time being, the use of soil from the above samples as a building material or for any other activity creates no significant harm.

\section{Conclusions}

This work considered the estimation of the level of NORMs and associated radiological hazards and risks of the iron ore deposited area in Wag-himra, Ethiopia. This study, NORM, was an analysis sample of soil from the mineral/iron ore deposit area. The NORMs identified in the samples were ${ }^{238} \mathrm{U}$, ${ }^{232} \mathrm{Th}$ and ${ }^{40} \mathrm{~K}$. The average radium equivalent activity values for the soil were $56.19 \mathrm{~Bq} / \mathrm{kg}$, which was below the internationally accepted value of $370 \mathrm{~Bq} / \mathrm{kg}$ [16]. In addition to this, the average external and gamma indexes were below the internationally accepted value of unity. The internal hazard index of the sample soil was slightly close to the international accepted value of a unit. Concerning the risks to members of the public, the average fatality cancer risks for this exposure pathway were analyzed according to the ICRP method. The recommendation proposed for all building materials must have external hazard, internal hazard and gamma indices that will be less than or equal to unity. Therefore, the soil from the study area can be used for construction purposes without causing any significant radiological hazards to humans for the time being. In general, the study area is mineral-rich. So the risk factor and significant harm of activity concentration may increase over time and due to extraction if it is performed.

\section{Conflicts of Interest}

The authors declare no conflict of interest

\section{Acknowledgements}

First, we would like to thank Almighty God for giving me an opportunity that we have received Masters Study. Next, we would like to express us deepest gratitude to us collogue physics department staff's their expert guidance, constructive comments, suggestions and encouragement without which this work.

\section{References}

[1] Podgorsak et al (2006). Radiation physics for medical physicist. $1^{\text {st }}$ edition. Printed in Germany, pp. 263.

[2] Merril Eisenbud and Thomas Gesell (1997). Environmental Radioactivity. Fourth edition, Academic press, USA, pp. 135-180.

[3] Edward L. Alpen (1998). Radiation Biophysics. Second edition, Academic press, USA, pp. 1-35.

[4] Ayham Assie and et al (2016). Determination of natural radioactivity by gamma spectroscopy in Balad soil, Iraq. Advances in Applied Science Research, 7 (1): 35-41.

[5] Belete Derib (2017). Evaluation, Characterization and management of Naturally Occurring Radioactive Materials and disused radioactive waste in Water and Soil Samples. Master's Thesis, Addis Ababa University, Institute of Technology, pp. 20-29.

[6] Beretka and P. J. Mathew (1985). Natural Radioactivity of Australian building materials. Health Phys, 48: 87-95.

[7] ERP (2012). United state Environmental radiation protection agency. pp. 8.

[8] Fanu A. (2011). Assessment of public exposure to naturally occurring radioactive materials from mining and mineral processing activities of tarkwa goldmine in Ghana, doctor of philosophy in chemistry, Kumasi, Ghana, pp. 51. 
[9] Glenn F. Knoll (2008). Radiation Detection and Measurement. Third edition, John Wiley \& Sons, Inc. New York/Chichester/, pp. 57-67.

[10] Gordon R. Gilmore (2008). Practical Gamma ray Spectrometry. $2^{\text {nd }}$ edition, John Wiley \& Sons Ltd, Warrington, UK, PP. 56-80.

[11] Herman Cember and Thoma. E. Johnson (2009). Introduction to Health physics. $4^{\text {th }}$ edition, the McGraw-Hill Company, pp. $135-240$.

[12] IAEA (2008). Naturally occurring radioactive material (NORM V). Printed by the IAEA in Austria, pp. 31.

[13] Janet A. Ademola (2014). Estimation of Annual Effective Dose Due to Ingestion of Natural Radio nuclides in Cattle in Tin Mining Area of Jos Plateau, Nigeria. Natural Science, 6: 255-261.
[14] Ranjit Kumer (2011). Research Methodology step-by-step guide for beginner. Third edition, SAGE Publications Ltd, pp. 186.

[15] Sami Alharbi (2016). Measurement and monitoring of naturally occurring radioactive materials for regulation. Submitted to the Science and Engineering Faculty, Queensland University of Technology, Radiology, Queensland university, pp. 9-23.

[16] UNSCEAR (2000). Sources and effects of ionizing radiation. UNSCEAR Report to the General Assembly, with Scientific Annexes, UN, New York, 1: 19-87.

[17] ICRP (2000). International Commission on Radiological Protection. protection of the Public in Situations of Prolonged Radiation Exposure, Publication 82, Elsevier Science, Oxford. 